Article

\title{
Synthesis and Surface Modification of Nanostructured F-Doped ZnO: Toward a Transducer for Label-Free Optical Biosensing
}

\author{
Giovanna Chianese $^{1}$, Monica Terracciano ${ }^{1}{ }^{D}$, Rosalba Moretta ${ }^{1,2}$, Paolo Cappiello ${ }^{1}$, \\ Giuseppe Vitiello $^{3}\left(\mathbb{D}\right.$, Antonio Aronne ${ }^{3}$, Chiara Schiattarella ${ }^{1,4} \mathbb{( D}$, Luca De Stefano ${ }^{1, *(\mathbb{D})}$ \\ and Ilaria Rea ${ }^{1}$ (D) \\ 1 National Research Council, Institute for Microelectronics and Microsystems, Unit of Naples, \\ 80131 Naples, Italy \\ 2 Department of Chemical Sciences, Federico II University of Naples, 80138 Naples, Italy \\ 3 Department of Chemical, Materials and Production Engineering, Federico II University of Naples, \\ 80138 Naples, Italy \\ 4 Department of Physics, Federico II University of Naples, 80138 Naples, Italy \\ * Correspondence: luca.destefano@na.imm.cnr.it; Tel.: +39-081-613-2375
}

Received: 9 July 2019; Accepted: 12 August 2019; Published: 16 August 2019

\begin{abstract}
In this work, the surface of nanostructured fluorine-doped $\mathrm{ZnO}(\mathrm{nZnO} \cdot \mathrm{F})$ is functionalized with protein A ( PrA), and used as a model biomolecule. The chemical procedure is characterized by several analytical techniques such as Fourier Transform Infrared Spectroscopy, water contact angle analysis, and fluorescence microscopy. The surface modification of $\mathrm{nZnO} \cdot \mathrm{F}$ by binding increasing concentrations of PrA is also investigated by two label-free optical techniques, i.e., the spectroscopic reflectometry and the steady-state photoluminescence. The results are compared with those obtained using undoped $\mathrm{nZnO}$ substrates in order to highlight the better performances of $\mathrm{nZnO} \cdot \mathrm{F}$ due to the fluorine doping. The results of this study pave the way for the design and realization of a $\mathrm{ZnO}$-based nanostructured platform for label-free optical sensing.
\end{abstract}

Keywords: nanostructured zinc oxide; hydrothermal synthesis; bioconjugation; photoluminescence

\section{Introduction}

A biosensor is an analytical device constituted by a biological recognition element, generally defined as a probe immobilized on a transduction system, which converts a molecular interaction into a useful signal. There are several types of biosensors based on different sensing recognition mechanisms such as amperometric, electrochemical, optical, and thermometric. In an optical biosensor, the interaction between the biomolecular probe, bound on its surface, and the target analyte is transduced in a change of an optical signal (e.g., phase, intensity, color, and fluorescence) [1-3]. In the last few decades, the market of optical biosensors has grown very rapidly due to their high sensitivity, specificity, real-time response, and the possibility of performing remote sensing in flammable environments.

The semiconductors currently used in the microelectronic industry, such as silicon and its related materials (silicon oxide, silicon nitrides, and porous silicon), have been extensively exploited in biosensor fabrication, and hundreds of papers and reviews can be found in recent literature [4-8]. On the other hand, nanostructured metal oxides showed great potential for the detection of biomolecules, owing to several characteristics such as the controllable size/shape, large specific surface area, biocompatibility, catalytic and optical properties, and chemical stability [9]. Among them, nanostructured zinc oxide $(\mathrm{nZnO})$ is considered an interesting transducer material due to its multifunctional characteristics. 
The $\mathrm{nZnO}$ is an $\mathrm{n}$-type semiconductor with a wide direct band gap of $3.37 \mathrm{eV}$, and a large excitonic binding energy of $60 \mathrm{meV}$, thus allowing an efficient excitonic emission even at room temperature $[10,11]$. Under UV laser irradiation, $\mathrm{nZnO}$ is able to emit intense photoluminescence (PL) of which the spectrum is characterized by a peak at $380 \mathrm{~nm}$, due to free exciton recombination and a broad visible band related to the surface and lattice defects [12]. Different methods for fabrication of nZnO-based devices are available, such as Vapor-Liquid-Solid growth (VLS), Metal Organic Chemical Vapor Deposition (MOCVD), and High-Pressure Pulsed Laser Deposition (HP-PLD) [13,14]. Recently, hydrothermal synthesis was proposed as an advantageous alternative approach because it requires mild experimental conditions, simple equipment, low-cost reagents, and it can be indifferently used on several surfaces [15].

One of the key issues in the developing of biosensors is the functionalization strategy used to correctly immobilize the bioprobes on the material surfaces. From this point of view, the nZnO allows covalent binding of the biomolecules on its surface by using a soft chemical strategy, preserving the specific functionalities of the biological compounds and controlling their orientation. The use of the $\mathrm{ZnO}$ nanowires obtained by the hydrothermal method as a photoluminescent biosensor was demonstrated [14].

In this work, nanostructured fluorine (F)-doped $\mathrm{ZnO}(\mathrm{nZnO} \cdot \mathrm{F})$ was directly grown on a crystalline silicon substrate via hydrothermal synthesis, and chemically modified in order to fabricate a technological platform for biosensing purposes [15]. $\mathrm{F}^{-}$ions, usually used as a doping precursor, played a significant role in the morphological, electrical and optical properties of nanostructured $\mathrm{ZnO}$ [16]. Extensive studies reported in Reference [15], demonstrated that $\mathrm{F}$ atoms mainly occupy oxygen vacancies present in the material, without producing any substantial change of plasma frequency but only the enhancement of scattering rate due to an increase of grain boundary density. A proper functionalization procedure was developed to covalently immobilize the Protein A (PrA), used as a model molecule on the semiconductor surface. The functionalized nZnO.F was characterized by the Fourier Transform Infrared Spectroscopy, water contact angle, and fluorescence microscopy. The surface modification with different concentrations of PrA was also studied by label-free optical techniques, spectroscopic reflectometry, and PL analysis. The results were compared with those obtained by investigating undoped $\mathrm{nZnO}$.

\section{Materials and Methods}

\subsection{Materials}

(3-Aminopropyl)triethoxysilane (APTES), toluene, bis(sulfosuccinimidyl)suberate $\left(\mathrm{BS}^{3}\right)$, and FITC-labeled Protein A were purchased from Sigma Aldrich (Milan, Italy). The chips were fabricated in collaboration with the Department of Chemical Engineering of the University of Naples Federico II.

\subsection{Hydrothermal Synthesis}

Nanostructured undoped and F-doped $\mathrm{ZnO}$ films were prepared by the following steps: A solution containing a 1:1 molar ratio of triethylamine (TEA) and zinc acetate dihydrate (ZAD) was firstly prepared by mixing TEA $(0.21 \mathrm{~mL})$ and ZAD $(0.33 \mathrm{~g})$ into ethanol $(90 \mathrm{~mL})$ under constant stirring. After complete dissolution of ZAD, water $(10 \mathrm{~mL})$ was added dropwise, producing a whitish suspension which was transferred within a Teflon recipient (the liquid volume corresponding to $75 \%$ of the whole). The same procedure was used to prepare the nanostructured F-doped $\mathrm{ZnO}(\mathrm{nZnO} \cdot \mathrm{F}$ ) sample, by adding a specific amount $(2.14 \mathrm{mg})$ of ammonium hydrogen fluoride $\left(\mathrm{NH}_{4} \mathrm{FHF}\right)$ in the starting solution to obtain a final atomic $\mathrm{F}$ concentration of 5 at.\%. Two silicon supports with sputtered $\mathrm{ZnO}$ thin films were alternatively immersed upside down in the prepared suspensions within the Teflon recipients and heated at $90^{\circ} \mathrm{C}$ for $4 \mathrm{~h}$. The obtained samples were rinsed with de-ionized water, dried with nitrogen, and finally calcined at $400{ }^{\circ} \mathrm{C}$ for $2 \mathrm{~h}$. 


\subsection{Functionalization Procedure}

Hydroxyl $(\mathrm{OH})$ groups were activated on the surfaces of nanostructured $\mathrm{ZnO}$ samples by exposing the devices to oxygen plasma for $40 \mathrm{~s}$. The cold plasma activation is a standard technique used to induce the formation of surface chemical functional groups through the use of plasma gases such as oxygen, hydrogen, nitrogen, and ammonia, which dissociate and react with the surface. Samples were then silanized using a 5\% APTES solution in anhydrous toluene for $30 \mathrm{~min}$ at room temperature. Excess ungrafted silane was removed by intensive washing in dry toluene followed by curing performed at $100{ }^{\circ} \mathrm{C}$ for $10 \mathrm{~min}$. Samples were treated with a $1.7 \mathrm{mM}$ solution of $\mathrm{BS}^{3}$ in PBS pH 7.4 at $4{ }^{\circ} \mathrm{C}$ for $5 \mathrm{~h}$. After the washing in PBS, samples were dried by a nitrogen stream and incubated with a $2 \mathrm{mg} / \mathrm{mL}$ solution of fluorescein-labeled Protein A (PrA*) in PBS pH 7.4 overnight at $4{ }^{\circ} \mathrm{C}$. Excess $\operatorname{PrA}^{*}$ was removed by washing the samples five times in PBS. Any variation of the optical signals (both reflectance and photoluminescence) of devices was not observed after the last washing step, demonstrating that the unbound or non-specific bound PrA was completely removed.

\subsection{Scanning Electron Microscopy}

Scanning electron microscopy was performed through a FESEM ULTRA-PLUS (Zeiss, Oberkochen, Germany) at $20 \mathrm{kV}$ with the SE2 detector and a $15.9 \mathrm{~mm}$ working distance. The samples were gold sputtered (3 $\mathrm{nm}$ thickness) with a HR208Cressington sputter coater.

\subsection{Fourier Transform Infrared Spectroscopy}

Surface chemical composition of samples was investigated by Fourier Transform Infrared (FTIR) spectroscopy. FTIR spectra were acquired before and after PrA immobilization using a Nicolet Continu $\mu \mathrm{m}$ XL (Thermo Scientific, Waltham, MA, USA) microscope in the wavenumber region of $4000-1200 \mathrm{~cm}^{-1}$ with a resolution of $4 \mathrm{~cm}^{-1}$.

\subsection{Water Contact Angle Measurements}

Water contact angle (WCA) measurements were performed to investigate the wettability of samples using a First Ten Angstroms FTA 1000 C Class coupled with drop shape analysis software. The WCA values reported in this work are the average of at least three measurements on the same sample.

\subsection{Fluorescence Microscopy}

Leica Z16 APO fluorescence macroscope equipped with a camera Leica DFC300 was used for the fluorescence analysis of the samples functionalized with $\operatorname{PrA} A^{*}$. The imaging was performed using an I3 filter cube constituted by a $450-490 \mathrm{~nm}$ band-pass excitation filter, a $510 \mathrm{~nm}$ dichromatic mirror and a $515 \mathrm{~nm}$ suppression filter.

\subsection{Label-Free Optical Spectroscopies}

The interaction between $\mathrm{nZnO} \cdot \mathrm{F}$ and $\mathrm{nZnO}$ samples and unlabeled PrA at different concentrations $(2 \mathrm{mg} / \mathrm{mL}(48 \mu \mathrm{M}) ; 4 \mathrm{mg} / \mathrm{mL}(95 \mu \mathrm{M}) ; 6 \mathrm{mg} / \mathrm{mL}(143 \mu \mathrm{M}))$ was investigated by using label-free optical techniques: Spectroscopic reflectometry and steady-state photoluminescence analysis.

Reflectivity spectra were acquired by sending a white light on the samples by means of a $Y$ optical reflection probe (Avantes). The same probe was used to guide the output signal to an optical spectrum analyzer (Ando AQ6315A). The spectra were acquired at normal incidence over the range 600-1200 nm with a resolution of $1 \mathrm{~nm}$. Reflectivity spectra reported in this work are the average of three measurements.

Steady-state photoluminescence (PL) spectra of samples were excited by a continuous wave $\mathrm{He}-\mathrm{Cd}$ laser at $325 \mathrm{~nm}$ (KIMMON Laser System). PL was collected at normal incidence to the surface of samples through a fiber, dispersed in a spectrometer (Princeton Instruments, Trenton, NJ, USA SpectraPro 300i), and detected using a Peltier cooled charge-coupled device (CCD) camera (PIXIS 100F). 
A long pass filter with a nominal cut-on wavelength of $350 \mathrm{~nm}$ was used to remove the laser line at the monochromator inlet.

\section{Results and Discussion}

The presence of $\mathrm{F}$ atoms as doping agent in $\mathrm{ZnO}$ powders strongly affected all the intrinsic properties of $\mathrm{ZnO}$ nanocrystals, in particular its morphology, by inducing the formation of a clear granular nanometric phase [16]. This effect was well evident when the fluorinated nZnO.F and the undoped $\mathrm{nZnO}$ films were directly grown on solid substrates and studied for comparison. Both nZnO.F and $\mathrm{nZnO}$ films were grown on flat crystalline silicon by a hydrothermal synthesis, which required a seed layer of $\mathrm{ZnO}$ sputtered on the substrates before the synthesis. Due to the nanometric features of these samples, their morphological characterization was performed by SEM imaging. The results, reported in Figure 1, highlighted an impressive difference of the morphology in the different materials: The $\mathrm{nZnO} \cdot \mathrm{F}$ appeared as a packed film constituted by flake-like nanograins of about $600 \mathrm{~nm}$; while the $\mathrm{nZnO}$ was formed by standard hexagonal nanocolumns of $200 \mathrm{~nm}$ in diameter almost perpendicular to the plane. The surface roughness of doped and undoped $\mathrm{nZnO}$ was measured by a profilometric technique; the $\mathrm{nZnO} \cdot \mathrm{F}$ was characterized by a rms (root mean squared) of $20 \pm 2 \mathrm{~nm}$, while the $\mathrm{nZnO}$ surface result was smoother (rms of only $9 \pm 1 \mathrm{~nm}$ ).

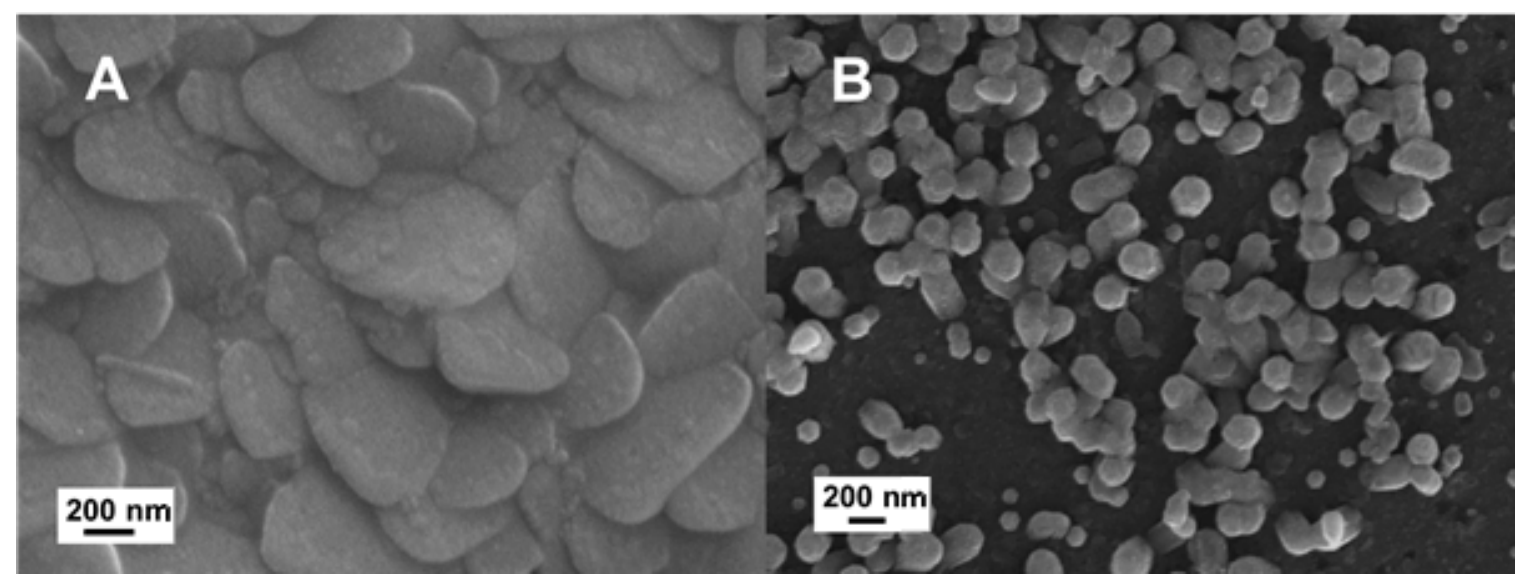

Figure 1. Representative SEM images of nanostructured fluorine (F)-doped $\mathrm{ZnO}(\mathrm{nZnO} \cdot \mathrm{F})(\mathbf{A})$ and $\mathrm{nZnO}(\mathbf{B})$.

The two samples were functionalized with FITC-labeled $\operatorname{PrA}\left(\operatorname{PrA}{ }^{*}\right)$ following the chemical procedure described in Scheme 1. PrA was used as a model molecule since it has great relevance from a sensing point of view and for the biosensors surface chemical modification. PrA is often covalently coupled to the surface of transducer materials by several methods which span from direct adsorption to click chemistry [17-19]. PrA can be found in nature as a virulence factor specific for Staphylococcus aureus, bound to glycans on the bacterial cell surface. PrA is also able to link to the von Willebrand factor that is a protein for the hemostasis process. Moreover, more important is the fact that $\operatorname{PrA}$ selectively binds the Fc-region of human antibodies, thus resulting essentially in the correct orientation of the antibodies fixed on a support surface.

The chemical modification strategy of $\mathrm{nZnO}$ and nZnO-F was based on two steps. In the first one, the covalent binding of a FITC-labelled PrA was monitored by the FT-IR spectroscopy, WCA analysis, and fluorescence imaging in order to assess the silanization of a zinc oxide nanostructured surface. The hydrothermal grown zinc oxide had a hydrophilic surface after the synthesis, which was made in aqueous solution (see Scheme 1 (1)). The presence of $\mathrm{OH}$ groups promoted the $\mathrm{Zn}-\mathrm{O}-\mathrm{Si}$ bounds after the silanization with APTES, resulting in an amino-terminated surface (Scheme 1 (2)). The $\mathrm{BS}^{3}$ crosslinker and the exposure to a PrA solution completed the functionalization procedure 
(Scheme 1 (3) and (4)). In the second step, increasing concentrations of PrA were grafted on both surfaces in search of which was better functionalized by the same procedure.

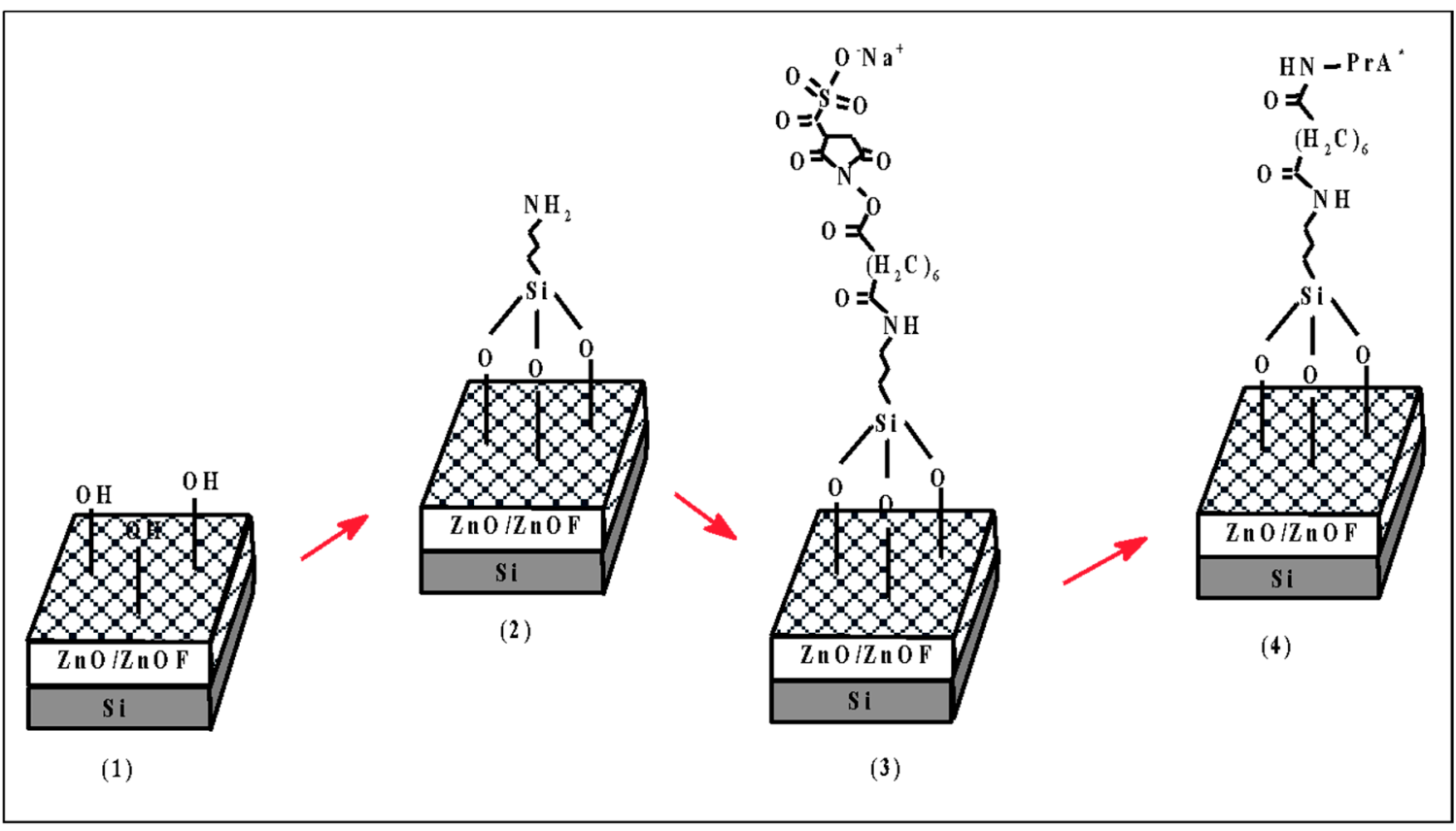

Scheme 1. Functionalization scheme of nZnO·F and nZnO surfaces. (1) Oxygen plasma. (2) Silanization by APTES. (3) $\mathrm{BS}^{3}$ crosslinker modification. (4) $\operatorname{PrA}^{*}$ immobilization.

Figure 2 shows the FT-IR spectra of the nZnO.F acquired before and after the last functionalization step with PrA*; spectra related to intermediate functionalization steps (i.e., APTES and $\mathrm{BS}^{3}$ ) were not reported because any substantial variation was not observed. The features at 1540 and $1400 \mathrm{~cm}^{-1}$ were attributed to asymmetric and symmetric stretching modes of the acetate groups (-COO) absorbed during the synthesis process [20]. The peaks at $1650 \mathrm{~cm}^{-1}$ and about $3300 \mathrm{~cm}^{-1}$, only visible in the spectrum of the functionalized sample, were due to the amide I band and to N-H stretching vibration of protein, respectively [21]. Differently, the FTIR spectrum of $\mathrm{nZnO}$, after the PrA* immobilization procedure, did not present any evident change, which corresponded to a very low amount of protein bound on its surface (data not shown here).

The surface wettability of $\mathrm{ZnO} \cdot \mathrm{F}$ and $\mathrm{nZnO}$ samples were investigated by measuring the WCA values before and after each functionalization step. The results are reported in Figure 3. Due to the hydrothermal synthesis process, samples were mostly hydrophobic; the WCA values of $(117 \pm 7)^{\circ}$ and $(110 \pm 10)^{\circ}$ were measured for $\mathrm{ZZnO}$ and $\mathrm{nZnO} \cdot \mathrm{F}$, respectively. After the plasma oxygen process, the hydroxyl groups activated on the sample surfaces induced a strong decreasing of the WCA values down to $(45 \pm 5)^{\circ}$ for the $\mathrm{ZZnO} \cdot \mathrm{F}$ and to $(61 \pm 9)^{\circ}$ for the $\mathrm{ZnO}$. As expected, after the amino-silanization process, increased values of WCA up to $(106 \pm 12)^{\circ}$ and $(98 \pm 2)^{\circ}$ were measured for the $\mathrm{nZnO} \cdot \mathrm{F}$ and the $\mathrm{nZnO}$, respectively, due to the replacement of $-\mathrm{OH}$ groups by the hydro-carbons and $-\mathrm{NH}_{2}$ functional groups of the APTES molecules. The high increase of the WCA values was attributed to an efficient capping of hydroxyl groups by the aminosilane, probably oriented in a way that mainly exposed the hydrophobic hydro-carbon groups [22].

The BS $^{3}$ crosslinker introduced the hydrophilic N-hydrosulfosuccinimide groups (NHS) on the surfaces, resulting in a WCA value decrease down to $(68 \pm 9)^{\circ}$, in the case of the nZnO.F, and to $(54 \pm 8)^{\circ}$ for the $\mathrm{nZnO}$. After the incubation with the PrA* the WCA values of both samples remained unchanged within the errors: This result was compatible with the presence of both the hydrophilic and hydrophobic domains, and characteristic of the protein structure [21]. 


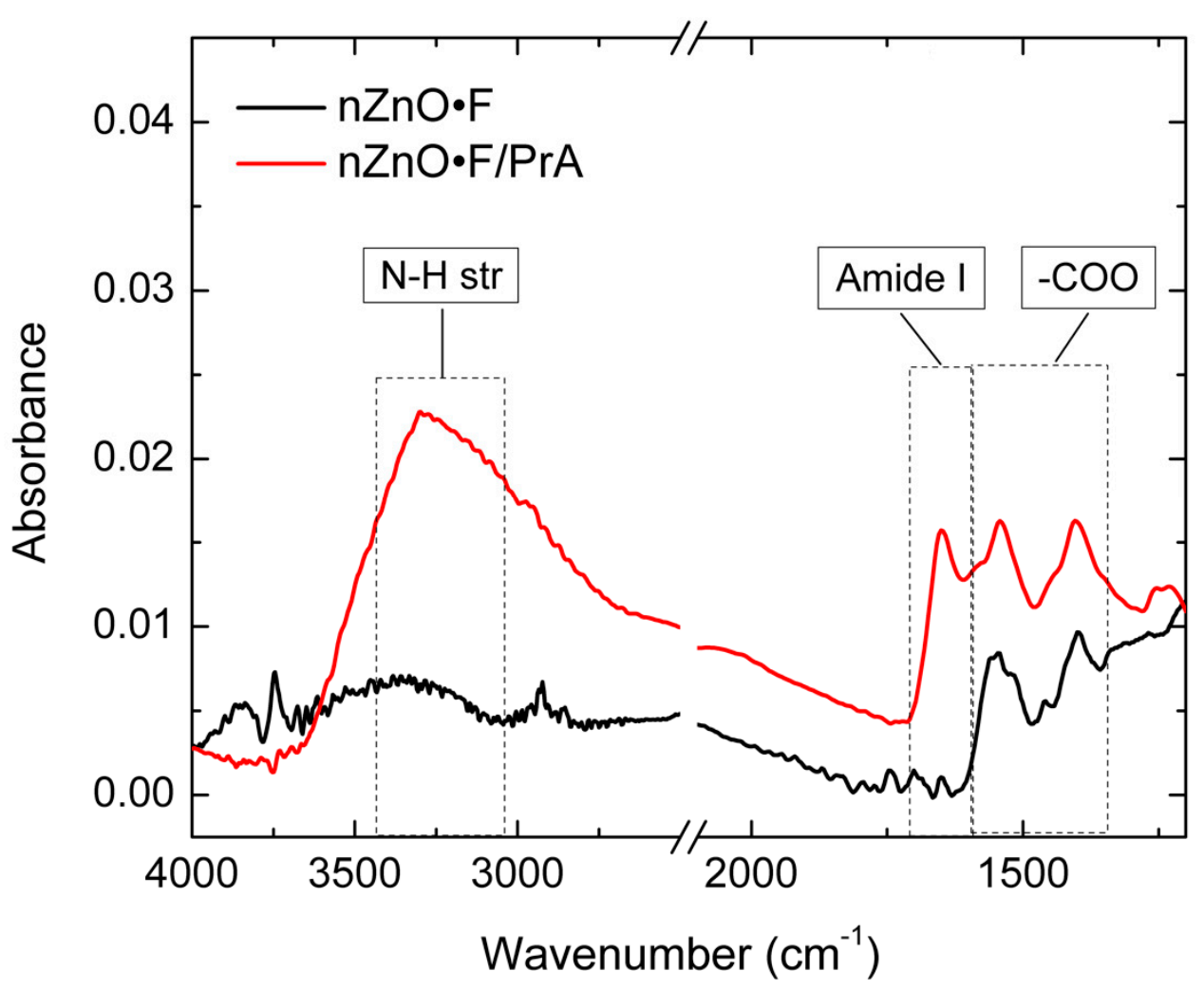

Figure 2. FTIR spectra of nZnO·F sample before (black line) and after (red line) functionalization with PrA.

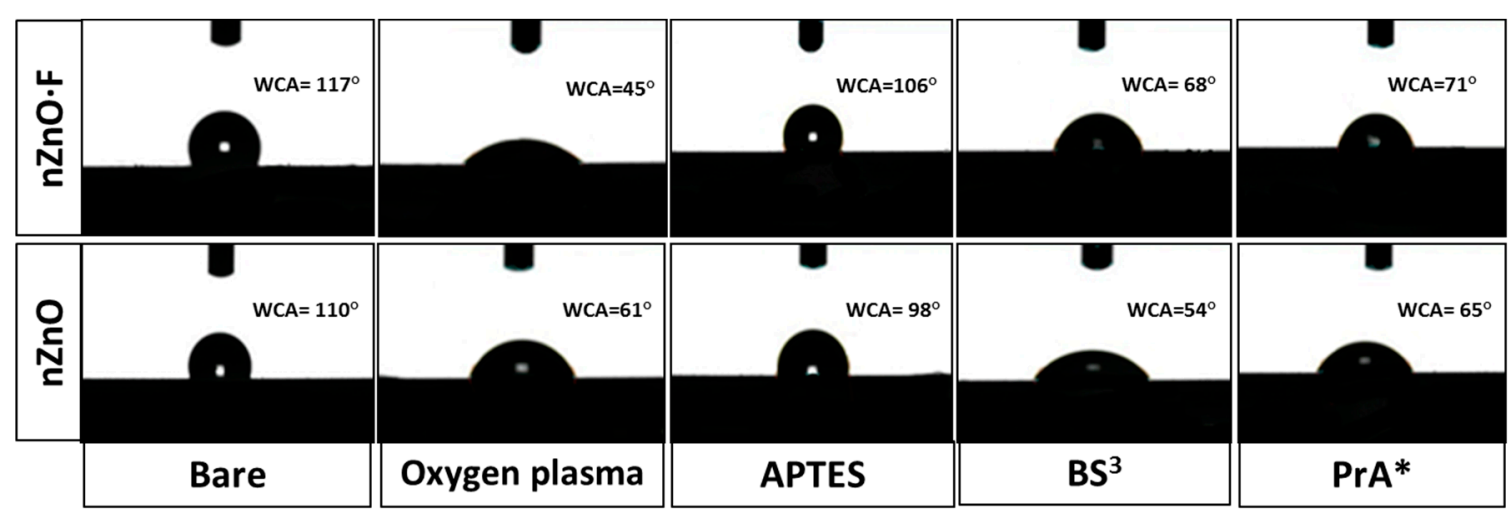

Figure 3. Wettability investigation of $\mathrm{nZnO} \cdot \mathrm{F}$ (upper line) and $\mathrm{nZnO}$ (lower line) samples. WCA measurements were performed after each functionalization step.

The fluorescence microscopy imaging was used to support the presence of the $\operatorname{PrA}{ }^{*}$ on the sample surfaces after the last functionalization step. The images, reported in Figure 4, showed a fluorescence homogeneously clustered on the whole surface of PrA*-modified nZnO.F (mean fluorescence intensity $=20 \pm 1$ counts), while only few luminescent spots, corresponding to a mean fluorescence intensity of $13 \pm 1$ counts, occurred on the surface of $\mathrm{nZnO}$ after PrA*. Analyzing the percentage difference between the values of the mean fluorescence intensities in both samples, we estimated that about $35 \%$ as much protein was immobilized on the doped one.

The control samples, i.e., the nZnO.F and nZnO without the PrA*, appeared completely dark (mean fluorescence intensity $=5 \pm 1$ ). The fluorescence microscopy imaging was thus in perfect agreement with the results obtained by FTIR spectroscopy. 


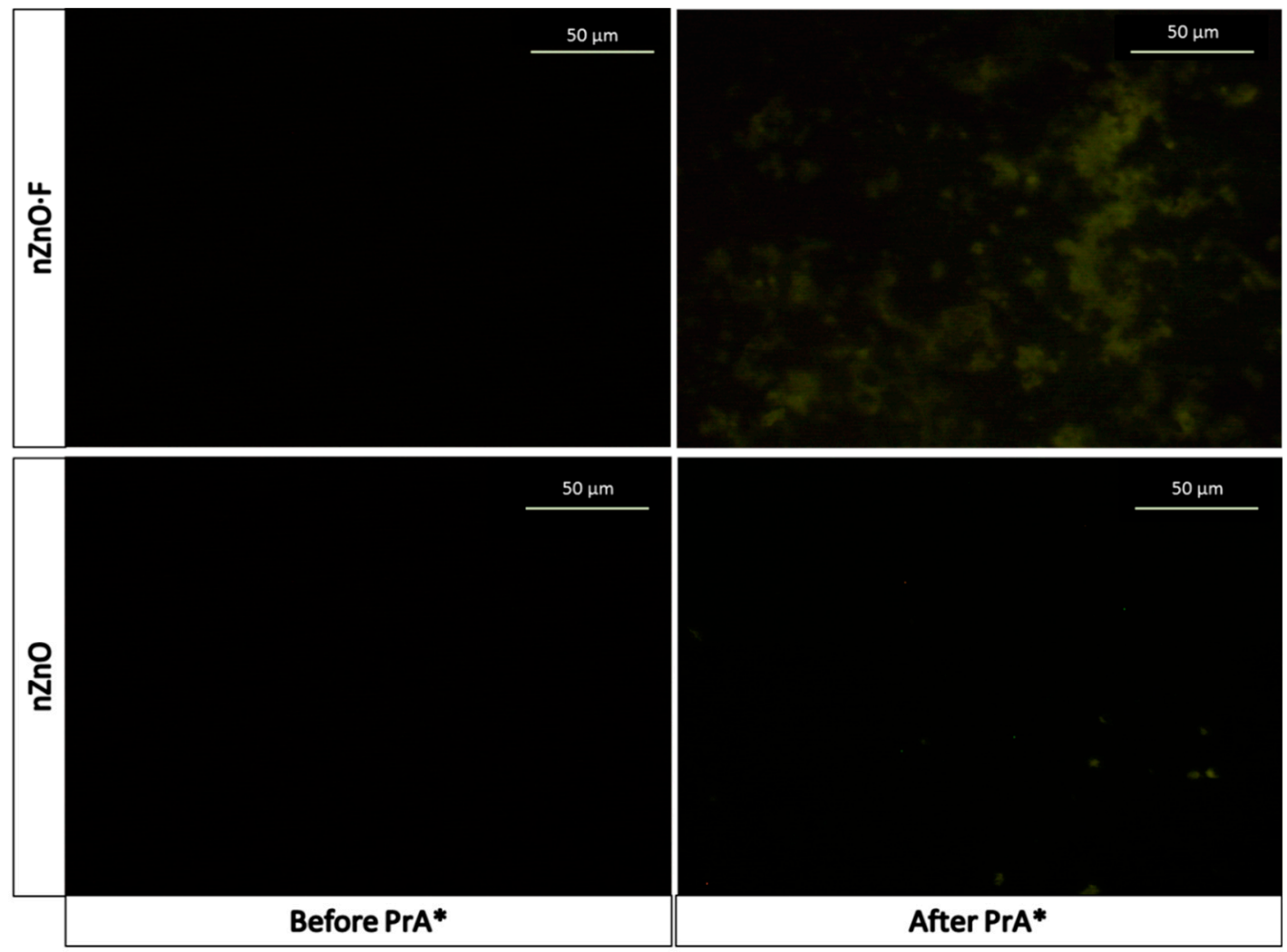

Figure 4. Fluorescence microscopy imaging of $\mathrm{nZnO} \cdot \mathrm{F}$ (upper line) and $\mathrm{nZnO}$ (lower line) before and after functionalization with $\operatorname{Pr} A^{*}$.

After the characterization of the surface functionalization by the standard methods of confirming the immobilization of the labeled protein, new samples of $\mathrm{nZnO} \cdot \mathrm{F}$ and $\mathrm{nZnO}$ were grown on silicon and functionalized with unlabeled PrA at different concentrations; in this case, the surface modification was monitored using two label-free techniques, i.e., the spectroscopic reflectometry and the photoluminescence analysis, exploiting the intrinsic optical properties of the semiconductor film.

The layers of nanostructured $\mathrm{ZnO}$ acted as Fabry-Perot interferometers from the optical point of view. Their reflectance spectra consisted of fringe patterns due to the interference occurring at air/nZnO·F (or nZnO) and nZnO.F (or nZnO)/bulk silicon interfaces. The optical thickness, OT, of a layer could be quantified as $n L$ where $n$ is the average refractive index of the material and $L$ is the physical thickness. The OT could be calculated counting the fringe maxima satisfying the relationship $m \lambda=2 \mathrm{~nL}$, with $m$ integer and $\lambda$ wavelength of the incident light. A faster method was based on the fast Fourier transform (FFT) of the reflectance spectrum; FFT of the spectrum was characterized by a peak whose position along $x$-axis was two times the optical thickness of the layer.

The covalent immobilization of PrA on the sample surfaces induced the red-shift of their reflectance spectra due to an increase of the optical thicknesses. Since the physical thickness $L$ was fixed, the optical thickness increased due to the change of the average refractive index caused by the infiltration of $\operatorname{PrA}$ inside the voids of the layers. Figure $5 \mathrm{~A}, \mathrm{C}$ report the reflectance spectra of $\mathrm{nZnO} \cdot \mathrm{F}$ and $\mathrm{nZnO}$ layers after the interaction with different concentrations of $\operatorname{PrA}$ (i.e., $2 \mathrm{mg} / \mathrm{mL} ; 4 \mathrm{mg} / \mathrm{mL} ; 6 \mathrm{mg} / \mathrm{mL}$ ); the increment of the OT was well evident from Figure 5B,D, which show the FFT of the spectra. By calculating the differences between the OT of the samples before and after the protein functionalization, maximum $\triangle \mathrm{OT}$ of $110 \mathrm{~nm}$ and $70 \mathrm{~nm}$ were determined in the case of $\mathrm{nZnO} \cdot \mathrm{F}$ and $\mathrm{nZnO}$, respectively. The result suggested that about $37 \%$ as much protein was immobilized on the surface of nZnO.F sample with respect to $\mathrm{nZnO}$ one; this value, calculated as the percentage difference between the two maxima $\triangle \mathrm{OT}$, was in agreement with that calculated by fluorescence imaging. Fitting $\Delta \mathrm{OT}$ data with a dose-response 
curve, the PrA concentration useful for surface saturation was estimated to be $4 \mathrm{mg} / \mathrm{mL}$ for both samples (Figure 5E).

A

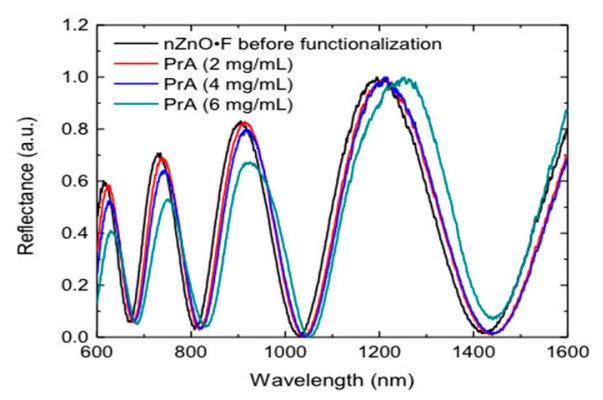

C

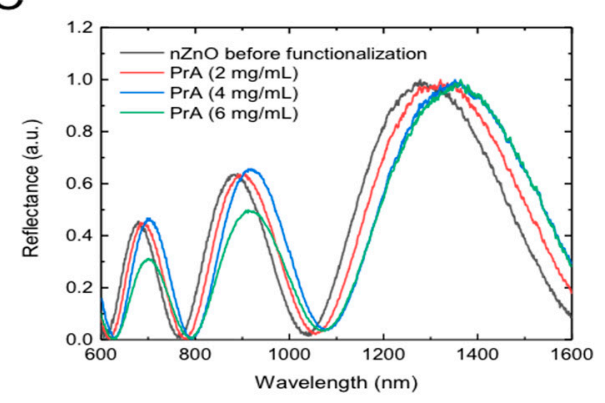

B
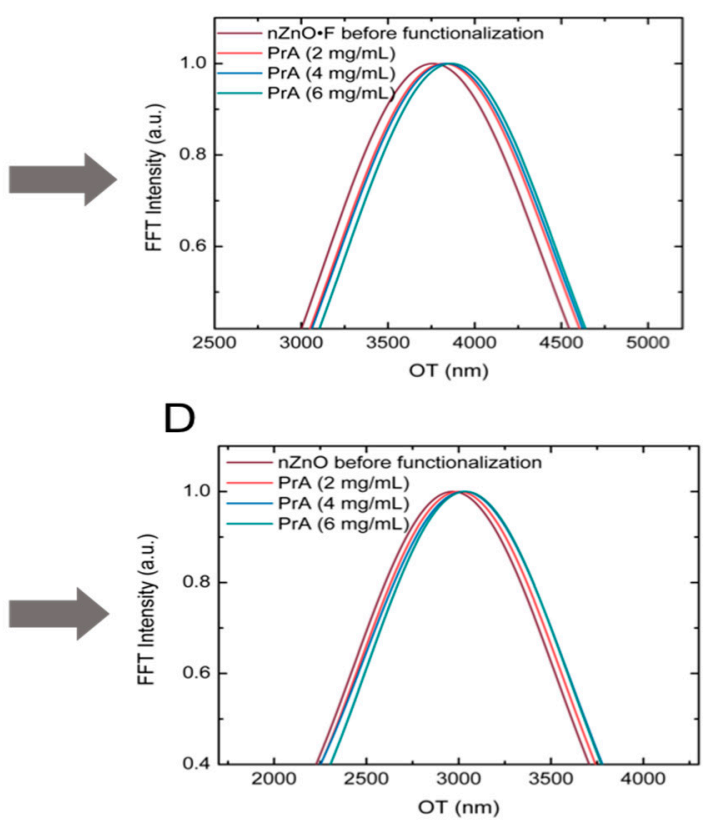

$\mathrm{E}$

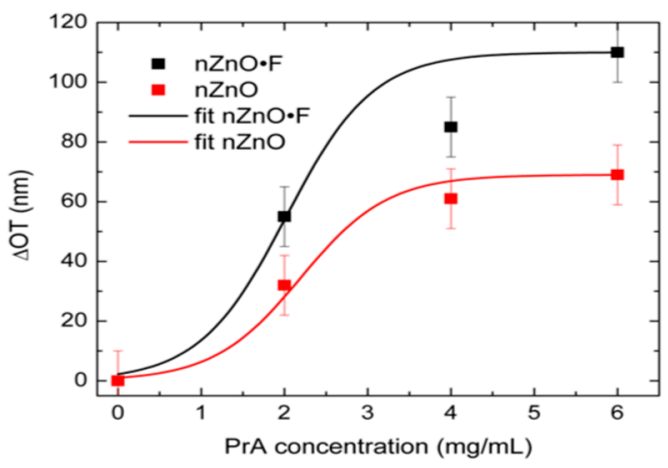

Figure 5. Reflectivity spectra of $\mathrm{nZnO} \cdot \mathrm{F}(\mathrm{A})$ and $\mathrm{nZnO}(\mathbf{C})$ before and after modification with different concentrations of PrA; corresponding Fourier transforms (B,D). $\triangle \mathrm{OT}$ as function of PrA concentrations, calculated for $\mathrm{nZnO} \cdot \mathrm{F}$ and $\mathrm{nZnO}$; experimental data were fitted by using a dose-response curve (E).

The PL emission of the nanostructured $\mathrm{ZnO}$ is sensitive to the chemical modification of the material surface and it can be used for monitoring the biomolecular interactions in the experiments of label-free optical sensing [14]. For this reason, the interaction between the $\mathrm{ZnO} \cdot \mathrm{F}$ and $\mathrm{nZnO}$ samples and the PrA was also investigated measuring their PL spectra. Figure 6A,B report the PL spectra of the $\mathrm{nZnO} \cdot \mathrm{F}$ and $\mathrm{nZnO}$, respectively, after the surface functionalization with $2 \mathrm{mg} / \mathrm{mL}, 4 \mathrm{mg} / \mathrm{mL}$ and 6 $\mathrm{mg} / \mathrm{mL}$ of PrA; the spectra of functionalized samples were compared with the spectra acquired before the functionalization. For both the materials, any variation of the peak at $380 \mathrm{~nm}$ ascribed to near band edge excitonic transitions, was not observed. On the contrary, the intensity of the broad visible band, included between 500 and $800 \mathrm{~nm}$ and mainly related to the surface defects, decreased at the increasing of protein concentration. By calculating the integrated PL (IPL) intensities and plotting them as a function of the PrA concentration (Figure 6B,D), a variation of $20 \%$ was obtained for the 
fluorine doped sample and only $5 \%$ for the undoped sample. The integrated PL intensity variations were calculated as:

$$
\Delta I_{P L}=\left(\frac{I_{P L}(0)-I_{P L}(6)}{I_{P L}(0)}\right) * 100
$$

The results of the optical investigations, i.e., the spectroscopic reflectometry and the photoluminescence spectroscopy, clearly demonstrated that nZnO.F could be functionalized with a higher efficiency with respect to the undoped $\mathrm{nZnO}$. This effect was mainly ascribed to the peculiar flake-like morphology of the fluorine-doped material, made of nanograins much larger than the $\mathrm{nZnO}$ nanocolumns and with a more exposed area that could sustain a stronger surface interaction with the PrA biomolecules.

The silanization procedure for the functionalization of nanostructured zinc oxide, undoped and fluorine doped, with protein A was already successfully used in the case of porous silicon [23]. Since silanization was well established in the substitution of Si-OH bonds by Si-C ones, which were much more stable from the thermodynamic point of view, we firstly verified that silanization was able to substitute $\mathrm{Zn}-\mathrm{OH}$ bonds by $\mathrm{Zn}-\mathrm{Si}-\mathrm{C}$ ones by grafting FITC-labelled protein A to both surfaces. Then, we exploited the amount of protein A that could be covalently linked to the semiconductors surface. Even if the porous silicon had a greater surface area, that could reach hundreds of $\mathrm{m}^{2} / \mathrm{gr}$, the nanostructured fluorine doped zinc oxide could be surface modified with a very similar concentration of protein A, from about $50 \mathrm{uM}$ up to $140 \mathrm{uM}$.
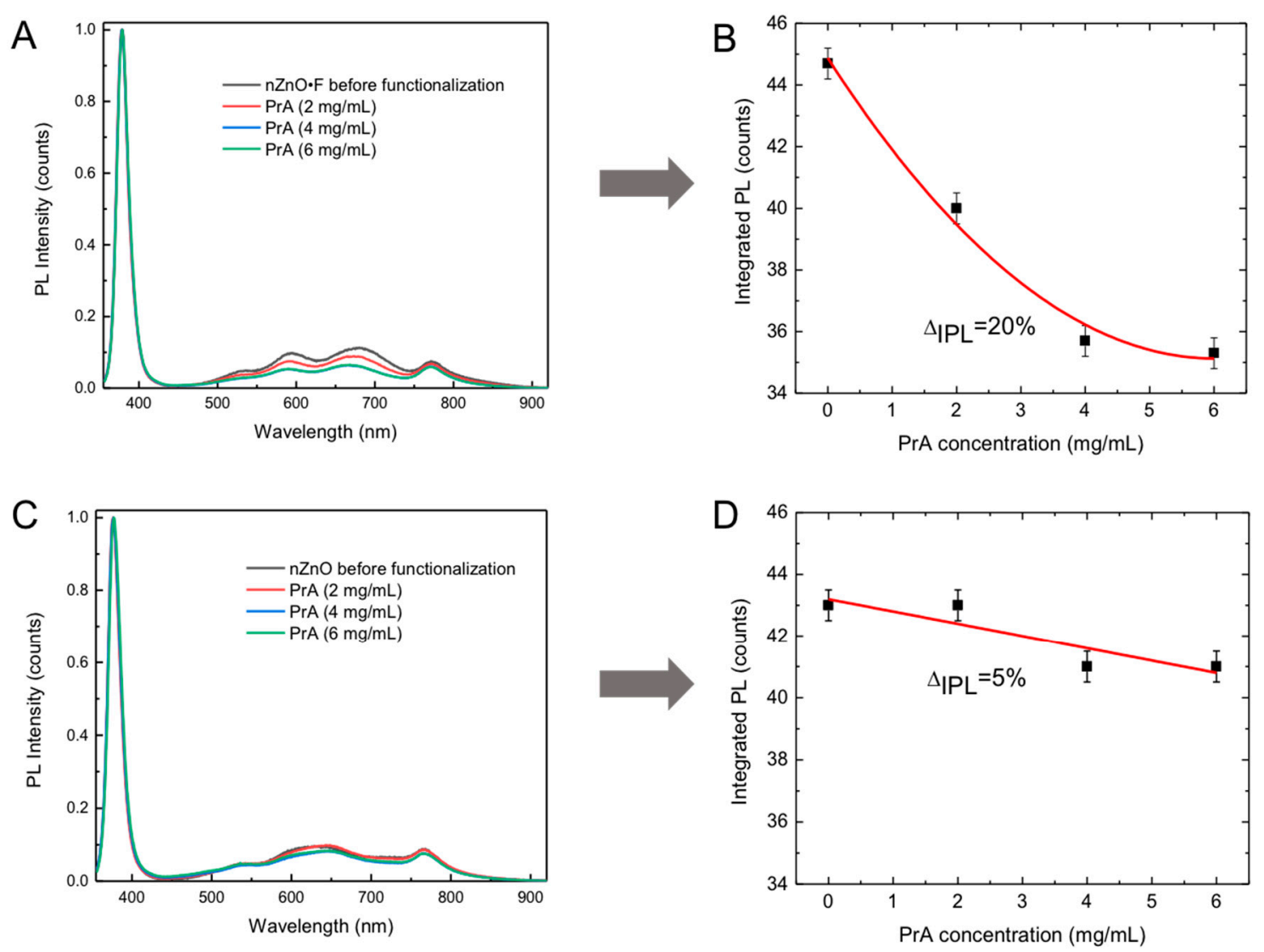

Figure 6. PL spectra of $\mathrm{nZnO} \cdot \mathrm{F}(\mathrm{A})$ and $\mathrm{nZnO}(\mathrm{C})$ measured after incubation with different concentrations of PrA; corresponding values of integrated PL as function of PrA concentration (B,D).

\section{Conclusions}

In this study, nZnO·F was synthesized on a silicon substrate by a hydrothermal process performed in presence of ammonium hydrogen fluoride. Compared to the undoped nZnO, nZnO.F was 
characterized by a rougher morphology constituted by nanograins of about $600 \mathrm{~nm}$ with a flake-like shape. A mild chemical procedure based on the aminosilane modification followed by a cross-linker (bis-sulfosuccinimidyl suberate) immobilization was used to covalently bind a model biomolecule, fluorescein-labeled protein A, on the nZnO·F surface. All the FTIR, WCA and fluorescence microscopy characterizations revealed a successful functionalization of the surface. The interaction between $\mathrm{nZnO} \cdot \mathrm{F}$ and increasing concentrations of unlabeled PrA was also characterized by two label-free optical techniques, i.e., the spectroscopic reflectometry and the photoluminescence analysis. The results of the optical characterizations demonstrated that the fluorine doped nZnO.F matrix could be better functionalized with respect to the undoped one, $\mathrm{nZnO}$; the effect was attributed to the wrinkled flake-like morphology, which allowed the immobilization of a higher percentage of the biomolecule under investigation compared to the highly packed hexagonal nanocolumns of the undoped sample. The data reported in this study also highlighted that nZnOFF could be effectively modified in order to fabricate a useful platform for label-free optical sensing.

Author Contributions: All authors equally contributed to this work.

Funding: This work was partially supported by the project POR FESR Campania 2014/2020 B63D18000250007.

Acknowledgments: The authors thank Maurizio Casalino of Institute for Microelectronics and Microsystems, National Research Council, for FFT analysis.

Conflicts of Interest: The authors declare no conflict of interest.

\section{References}

1. Holzinger, M.; le Goff, A.; Cosnier, S. Nanomaterials for biosensing applications: A review. Front. Chem. 2014, 2, 1-10. [CrossRef] [PubMed]

2. Bhat, S.S.; Qurashi, A.; Khanday, F.A. ZnO nanostructures based biosensors for cancer and infectious disease applications: Perspectives, prospects and promises. TrAC Trends Anal. Chem. 2017, 86, 1-13. [CrossRef]

3. Gooding, J.J. Biosensor technology for detecting biological warfare agents: Recent progress and future trends. Anal. Chim. Acta 2006, 559, 137-151. [CrossRef]

4. Tripathy, N.; Kim, D.-H. Metal oxide modified ZnO nanomaterials for biosensor applications. Nano Converg. 2018, 5, 27. [CrossRef] [PubMed]

5. De Stefano, L.; Oliviero, G.; Amato, J.; Borbone, N.; Piccialli, G.; Mayol, L.; Rendina, I.; Terracciano, M.; Rea, I. Aminosilane functionalizations of mesoporous oxidized silicon for oligonucleotide synthesis and detection. J. R. Soc. Interface 2013, 10, 160. [CrossRef] [PubMed]

6. De Stefano, L.; Rossi, M.; Staiano, M.; Mamone, G.; Parracino, A.; Rotiroti, L.; Rendina, I.; Rossi, M.; D’Auria, S. Glutamine-binding protein from escherichia coli specifically binds a wheat gliadin peptide allowing the design of a new porous silicon-based optical biosensor. J. Proteome Res. 2006, 5, 1241-1245. [CrossRef] [PubMed]

7. De Stefano, L.; Moretti, L.; Rendina, I.; Rossi, A.M. Time-resolved sensing of chemical species in porous silicon optical microcavity. Sens. Actuators B Chem. 2004, 100, 168-172. [CrossRef]

8. Arshavsky-Graham, S.; Massad-Ivanir, N.; Segal, E.; Weiss, S. Porous silicon-based photonic biosensors: Current status and emerging applications. Anal. Chem. 2018, 91, 441-467. [CrossRef]

9. Kong, Y.C.; Yu, D.P.; Zhang, B.; Fang, W.; Feng, S.Q. Ultraviolet-emitting ZnO nanowires synthesized by a physical vapor deposition approach. Appl. Phys. Lett. 2001, 78, 407-409. [CrossRef]

10. Park, W.I.; Jun, Y.H.; Jung, S.W.; Yi, G.C. Excitonic emissions observed in ZnO single crystal nanorods. Appl. Phys. Lett. 2003, 82, 964-966. [CrossRef]

11. Kumar, S.A.; Chen, S.M. Nanostructured zinc oxide particles in chemically modified electrodes for biosensor applications. Anal. Lett. 2008, 41, 141-158. [CrossRef]

12. Okada, T.; Agung, B.H.; Nakata, Y. ZnO nano-rods synthesized by nano-particle-assisted pulsed-laser deposition. Appl. Phys. A Mater. Sci. Process. 2004, 79, 1417-1419. [CrossRef]

13. Park, W.I.; Yi, G.C.; Kim, M.; Pennycook, S.J. ZnO nanoneedles grown vertically on Si substrates by non-catalytic vapor-phase epitaxy. Adv. Mater. 2002, 14, 1841-1843. [CrossRef] 
14. Politi, J.; Rea, I.; Dardano, P.; de Stefano, L.; Gioffrè, M. Versatile synthesis of ZnO nanowires for quantitative optical sensing of molecular biorecognition. Sens. Actuators B Chem. 2015, 220, 705-711. [CrossRef]

15. Papari, G.P.; Silvestri, B.; Vitiello, G.; De Stefano, L.; Rea, I.; Luciani, G.; Aronne, A.; Andreone, A. Morphological, structural, and charge transfer properties of F-doped $\mathrm{ZnO}$ : A spectroscopic investigation. J. Phys. Chem. C 2017, 121, 16012-16020. [CrossRef]

16. Zhang, J.; Liu, T.; Zhang, Y.; Zeng, W.; Pan, F.; Peng, X. Hydrothermal synthesis and growth mechanisms of different $\mathrm{ZnO}$ nanostructures and their gas-sensing properties. J. Mater. Sci. Mater. Electron. 2015, 26, 1347-1353. [CrossRef]

17. Luo, B.; Wu, S.; Zou, W.; Zhang, Z.; Zhao, M.; Shi, S.; Yan, Z. Label-free immunoassay for porcine circovirus type 2 based on excessively tilted fiber grating modified with staphylococcal protein A. Biosens. Bioelectron. 2016, 86, 1054-1060. [CrossRef] [PubMed]

18. Vranken, T.; Redeker, E.S.; Miszta, A.; Billen, B.; Hermens, W.; de Laat, B.; Cleij, T.J. In situ monitoring and optimization of CuAAC-mediated protein functionalization of biosurfaces. Sens. Actuators B Chem. 2017, 238, 992-1000. [CrossRef]

19. Urmann, K.; Reich, P.; Walter, J.G.; Beckmann, D.; Segal, E.; Scheper, T. Rapid and label-free detection of protein a by aptamer-tethered porous silicon nanostructures. J. Biotechnol. 2017, 257, 171-177. [CrossRef]

20. Socrates, G. Infrared and Raman Characteristic Group Frequencies: Tables and Charts, 3rd ed.; Wiley and Sons: Chichester, UK, 2001; Volume 124.

21. Brown, N.L.; Bottomley, S.P.; Scawen, M.D.; Gore, M.G. A study of the interactions between an IgG-binding domain based on the B domain of staphylococcal protein A and rabbit IgG. Appl. Biochem. Biotechnol. Part B Mol. Biotechnol. 1998, 10, 9-16. [CrossRef]

22. Kyaw, H.H.; Al-Harthi, S.H.; Sellai, A.; Dutta, J. Self-organization of gold nanoparticles on silanated surfaces. Beilstein J. Nanotechnol. 2015, 6, 2345-2353. [CrossRef] [PubMed]

23. Moretta, R.; Terracciano, M.; Rea, I.; Casalino, M.; Dardano, P.; De Stefano, L. Functionalization of macroporous silicon for optical detection of bacteria. In Proceedings of the 19th Italian National Conference on Photonic Technologies Fotonica IET 2017, Padua, Italy, 11-18 June 2017; pp. 1-3.

(C) 2019 by the authors. Licensee MDPI, Basel, Switzerland. This article is an open access article distributed under the terms and conditions of the Creative Commons Attribution (CC BY) license (http://creativecommons.org/licenses/by/4.0/). 